\title{
Measurement of Serum Lipid Level in Children with Congenital Heart Diseases
}

Abdulmonam Almokhtar Embark Omar', Amr Megahed Abouelnaga ${ }^{1}$,

Amal Mohamed Abd El Latef ${ }^{1}$, Samar Mahmoud Abdelhalim Sharaf ${ }^{2}$

Departments of ${ }^{1}$ Pediatrics and ${ }^{2}$ Clinical Pathology, Faculty of Medicine - Zagazig University, Egypt

*Corresponding author: Abdulmonam Almokhtar Embark Omar, Mobile: (+20) 01094884925,

E-mail: abdalmoname1983@gmail.com

\section{ABSTRACT}

Background: The lipid profile is an important and independent predictor of coronary heart disease is. This process relates to cholesterol concentration, accumulation and deposition of lipids on the arterial wall.

Objective: The aim of this study was the measurement of serum lipid profile (cholesterol, triglycerides, high-density lipoprotein (HDL) and low-density lipoprotein (LDL) in children with congenital heart diseases and to compare the results with those of healthy children. Patients and methods: This case-control study was carried out from July 2020 to December 2020 in Cardiology Unit of Pediatric Department Outpatient Clinic, Zagazig University Hospital on 44 children. Patients were divided into: Group (I): (Case group) included 22 children with congenital heart diseases, and Group (II) (control group) included 22 healthy children. All patients were subjected to dimensional transthoracic echocardiography with color flow Doppler (Vivid 7 dimension apparatus) and Laboratory investigations (total cholesterol, triglycerides, lowdensity lipoprotein (LDL), high-density lipoprotein (HDL). Results: The most frequent cardiac defect was ASD (22.7\%) followed by VSD (13.6\%), common A-V canal (9.1\%), mitral regurgitation (9.1\%), pulmonary regurgitation (9.1\%), and PDA (9.1\%). $18.2 \%$ of the studied patients had cyanotic congenital heart disease (CHD) and $81.8 \%$ had non-cyanotic CHD. There was statistically significant differences between the studied groups in lipid profile as case group had higher cholesterol, triglyceride, LDL and lower HDL than control group. Conclusion: We concluded in this study that patients had significantly higher serum lipid levels than age and sex-matched controls in light of these findings.

Keywords: Congenital Heart disease, Lipids, Dyslipidemia.

\section{INTRODUCTION}

Congenital heart diseases (CHD) are structural problems that arise from abnormal formation of the heart or major blood vessels. It is the commonest of all congenital lesions and is the most common type of heart diseases among children ${ }^{(\mathbf{1})}$. The global incidence rate of CHD is 6.8 to 9.0 per 1000 live births. Its most common subtypes are atrial septal defect, ventricular septal defect, patent ductus arteriosus, pulmonary stenosis, and tetralogy of Fallot. Depending on the presence of a right to left shunt, congenital heart disease patients can be divided into two groups; acyanotic and cyanotic (2).

Dyslipidemia is an important etiological factor in the development of cardiovascular disease (CVD), which is a leading cause of death worldwide as CVD begins in childhood ${ }^{(3)}$. An important and independent predictor of coronary heart disease is the lipid profile. This process relates to cholesterol concentration, accumulation and deposition of lipids on the arterial wall. The most important consequences of dyslipidemia are atherosclerosis and coronary artery disease due to the occlusion of the coronary arteries, ischemic heart disease (IHD) and myocardial infarction (MI). Many factors such as overweight, hypertension (HTN), diabetes mellitus (DM), smoking and low physical activity lead to increased serum lipid levels and consequently atherosclerosis ${ }^{(4)}$.With advances in pediatric cardiology, early physical examination and diagnosis, medical treatment, surgical methods, and postoperative care made the prevalence of $\mathrm{CHD}$ in adults has risen in relation to children, and the number of adults living with CHD is expected to continue its upsurge. It is presumed that there are more adults with CHD living than there are children with CHD. Accordingly, control of lipid levels and other risk factors has gained considerable significance ${ }^{(5)}$. So it is suggested to screen and treat dyslipidemia to prevent atherosclerosis since childhood and is important to evaluate prevalence of dyslipidemia in children with congenital heart disease ${ }^{(4)}$. The aim of this study was the measurement of serum lipid profile (cholesterol, triglycerides, high-density lipoprotein (HDL) and low-density lipoprotein (LDL) in children with congenital heart diseases and to compare the results with those of healthy children.

\section{PATIENTS AND METHODS}

This case-control study was carried out from July 2020 to December 2020 in Cardiology Unit of Pediatric Department Outpatient Clinic, Zagazig University Hospital on 44 children. Their ages ranged from 2 to 10 years old. The study groups were divided into: Group (I): (Case group): Which include 22 children (11 males and 11 females) with congenital heart diseases, and Group (II): (control group): Which include 22 healthy children (11 males and 11 females).

\section{Ethical approval:}

Written informed consent was obtained from all participants' parents and the study was approved by the Research Ethical Committee, Faculty of Medicine, Zagazig University. The work hasd been carried out in accordance with The Code of Ethics of the World Medical Association (Declaration of Helsinki) for studies involving humans. 
Inclusion criteria: Children with congenital heart defects (cyanotic and a cyanotic heart defects) confirmed by echocardiography. Control group of healthy children. Children aged from 2 to 10 years old, both males and females.

Exclusion criteria: Children receiving cholesterol lowering drugs and corticosteroids. Patients with myeloproliferative diseases, chronic liver or kidney diseases and diabetes mellitus which might affect lipid level. Children with heart diseases other than congenital heart diseases.

All patients were subjected to full history taking and full clinical examination. Any patient had tachypnea, tachycardia, grunting and intercostal retraction was considered to have respiratory distress. Echocardiography examination. Laboratory investigations (total cholesterol, triglycerides, low-density lipoprotein (LDL) and high-density lipoprotein (HDL).

Lipid profile blood sample: $3 \mathrm{ml}$ whole blood were collected then centrifuged to determine serum lipid level (total cholesterol, triglycerides, low-density lipoprotein (LDL) and high-density lipoprotein (HDL)). Quantitative determination of cholesterol IVD, Quantitative determination of HDL cholesterol IVD, and Quantitative determination of triglycerides IVD according to Young ${ }^{(6)}$.

\section{Statistical Analysis}

The collected data were coded, processed and analyzed using the SPSS (Statistical Package for Social Sciences) version 22 for Windows ${ }^{\circledR}$ (IBM SPSS Inc, Chicago, IL, USA). Data were tested for normal distribution using Shapiro Walk test. Qualitative data were represented as frequencies and relative percentages. Chi square test $(\chi 2)$ to calculate difference between two or more groups of qualitative variables. Quantitative data were expressed as mean \pm SD. Independent samples t-test was used to compare between two independent groups of normally distributed variables (parametric data). $\mathrm{P}$ value $\leq 0.05$ was considered significant.

\section{RESULTS}

- There was no statistically significant difference between the studied groups concerning demographic characteristics (Table 1).

- The most frequent cardiac defect was ASD (22.7\%) followed by VSD (13.6\%), common A-V canal $(9.1 \%)$, mitral regurgitation $(9.1 \%)$, pulmonary regurgitation (9.1\%), and PDA $(9.1 \%) .18 .2 \%$ of the studied patients had cyanotic CHD and $81.8 \%$ had non-cyanotic CHD (Table 2).

- There were significant differences between the studied groups in lipid profile as case group had higher cholesterol, triglyceride, LDL and lower HDL than control group (Table 3).

- There was no significant difference between cyanotic and non-cyanotic CHD in lipid profile (Table 4).

- There was no significant correlation between age and lipid profile in the studied groups (Table 5).

- There was significant association between sex and lipid profile as females had significantly higher serum triglycerides than males (Table 6).

Table (1): Demographic characteristics of the studied groups

\begin{tabular}{|c|c|c|c|c|}
\hline Variables & $\begin{array}{c}\text { Case group } \\
(n=22)\end{array}$ & $\begin{array}{c}\text { Control group } \\
(n=22)\end{array}$ & $\begin{array}{c}\text { Test of } \\
\text { sig. }\end{array}$ & $\mathbf{P}$ \\
\hline $\begin{array}{c}\text { Age (years): } \\
\text { Mean } \pm \text { SD } \\
\text { Median } \\
\text { Range }\end{array}$ & $\begin{array}{l}5.6 \pm 2.8 \\
5.0 \\
2.0-10.0\end{array}$ & $\begin{array}{l}5.6 \pm 2.3 \\
\quad 4.0 \\
2.0-10.0\end{array}$ & $\begin{array}{c}\text { MW } \\
1.2\end{array}$ & $\begin{array}{l}0.3 \\
\text { NS }\end{array}$ \\
\hline $\begin{array}{c}\text { Sex, } \mathrm{n}(\%): \\
\text { Male } \\
\text { Female }\end{array}$ & $\begin{array}{l}11(50.0 \%) \\
11(50.0 \%)\end{array}$ & $\begin{array}{l}11(50.0 \%) \\
11(50.0 \%)\end{array}$ & NA & NA \\
\hline $\begin{array}{c}\text { Residence, n (\%): } \\
\text { Rural } \\
\text { Urban } \\
\end{array}$ & $\begin{array}{c}14(63.6 \%) \\
8(36.4 \%) \\
\end{array}$ & $\begin{array}{c}17(77.3 \%) \\
5(22.7 \%) \\
\end{array}$ & $\begin{array}{l}\chi^{2} \\
1.0\end{array}$ & $\begin{array}{l}0.3 \\
\text { NS } \\
\end{array}$ \\
\hline $\begin{array}{c}\text { Rank of child, n (\%): } \\
1^{\text {st }} \\
2^{\text {nd }} \\
3^{\text {rd }} \\
4^{\text {th }} \\
\end{array}$ & $\begin{array}{l}2(9.1 \%) \\
8(36.4 \%) \\
6(27.3 \%) \\
6(27.3 \%) \\
\end{array}$ & $\begin{array}{c}4(18.2 \%) \\
10(45.5 \%) \\
6(27.3 \%) \\
2(9.1 \%) \\
\end{array}$ & $\begin{array}{l}\chi^{2} \\
2.5\end{array}$ & $\begin{array}{l}0.1 \\
\text { NS }\end{array}$ \\
\hline $\begin{array}{l}\text { Consanguinity, } \mathrm{n}(\%) \text { : } \\
\text { Positive } \\
\text { Negative }\end{array}$ & $\begin{array}{c}9(40.9 \%) \\
13(59.1 \%)\end{array}$ & $\begin{array}{c}5(22.7 \%) \\
17(77.3 \%)\end{array}$ & $\begin{array}{l}\chi^{2} \\
1.7\end{array}$ & $\begin{array}{l}0.2 \\
\text { NS }\end{array}$ \\
\hline $\begin{array}{l}\text { Family history of cardiac diseases, } \mathrm{n}(\%) \text { : } \\
\text { Positive } \\
\text { Negative }\end{array}$ & $\begin{array}{c}3(13.6 \%) \\
19(86.4 \%) \\
\end{array}$ & $\begin{array}{c}0(0.0 \%) \\
22(100 \%) \\
\end{array}$ & Fisher & $\begin{array}{l}0.2 \\
\text { NS } \\
\end{array}$ \\
\hline
\end{tabular}

SD: Standard deviation. NA: Not applicable. $\chi^{2}$ : Chi square test, MW: Mann Whitney test. NS: Non-significant (P>0.05) 
Table (2): Echo findings of the studied cases

\begin{tabular}{||l|c|}
\hline \multicolumn{1}{|c|}{ Echo findings } & Case group (n=22) \\
\hline ASD & $5(22.7 \%)$ \\
\hline VSD & $3(13.6 \%)$ \\
\hline Common A-V canal & $2(9.1 \%)$ \\
\hline Mitral regurgitation & $2(9.1 \%)$ \\
\hline Pulmonary regurgitation & $2(9.1 \%)$ \\
\hline PDA & $2(9.1 \%)$ \\
\hline PFO & $1(4.5 \%)$ \\
\hline Coarctation of aorta & $1(4.5 \%)$ \\
\hline Complete endocardial cushion defect & $1(4.5 \%)$ \\
\hline Outlet VSD with pulmonary stenosis & $1(4.5 \%)$ \\
\hline Sever valvular pulmonary stenosis & $1(4.5 \%)$ \\
\hline Truncus arteriosus type 1 & $1(4.5 \%)$ \\
\hline
\end{tabular}

CHD: Congenital heart disease. VSD: Ventricular septal defect, ASD: Atrial septal defect. PDA: patent ductus arteriosus, Common A-V Canal: common atrial ventricular canal. PFO: Patent foramen oval. $18.2 \%$ of the studied patients had cyanotic CHD and $81.8 \%$ had non-cyanotic CHD.

Table (3): Lipid profile of the studied groups

\begin{tabular}{|c|c|c|c|c|}
\hline Variables & $\begin{array}{c}\text { Case group } \\
(\mathrm{n}=22)\end{array}$ & $\begin{array}{c}\text { Control group } \\
(\mathrm{n}=22)\end{array}$ & $\begin{array}{l}\text { Test of } \\
\text { sig. }\end{array}$ & $\mathbf{P}$ \\
\hline $\begin{array}{c}\text { Total cholesterol }(\mathrm{mg} / \mathrm{dl}): \\
\text { Mean } \pm \text { SD }\end{array}$ & $130.3 \pm 17.6$ & $107.2 \pm 8.9$ & $\begin{array}{l}\mathrm{t} \text { test } \\
4.0\end{array}$ & $\begin{array}{c}<0.001 \\
\text { HS }\end{array}$ \\
\hline $\begin{array}{r}\text { Triglyceride }(\mathrm{mg} / \mathrm{dl}): \\
\text { Mean } \pm \text { SD }\end{array}$ & $115.7 \pm 27.1$ & $78.2 \pm 14.4$ & $\begin{array}{l}\text { t test } \\
2.6\end{array}$ & $0.01 \mathrm{~S}$ \\
\hline $\begin{array}{c}\text { LDL (mg/dl): } \\
\text { Mean } \pm \text { SD }\end{array}$ & $66.4 \pm 15.6$ & $38.1 \pm 6.7$ & $\begin{array}{c}\mathrm{t} \text { test } \\
5.1\end{array}$ & $\begin{array}{c}<0.001 \\
\text { HS }\end{array}$ \\
\hline $\begin{array}{l}\text { HDL }(\mathrm{mg} / \mathrm{dl}): \\
\quad \text { Mean } \pm \text { SD }\end{array}$ & $40.7 \pm 9.6$ & $53.5 \pm 7.5$ & $\begin{array}{c}\text { student } \mathrm{t} \\
\text { test } \\
3.3\end{array}$ & $\begin{array}{c}0.001 \\
\mathrm{~S}\end{array}$ \\
\hline
\end{tabular}

SD: Standard deviation. student $\mathrm{t}$ test. S: Statistically significant $(\mathrm{P}<0.05)$. HS: Highly statistically significant $(<0.001)$

Table (4): Comparison between cyanotic and non-cyanotic CHD in lipid profile

\begin{tabular}{||c|c|c|c|c||}
\hline Variables & $\begin{array}{c}\text { Cyanotic CHD } \\
(\mathbf{n = 4})\end{array}$ & $\begin{array}{c}\text { Non-cyanotic } \\
\text { CHD }(\mathbf{n = 1 8})\end{array}$ & $\begin{array}{c}\text { Test of } \\
\text { sig. }\end{array}$ & P \\
\hline Total cholesterol (mg/dl): & & & MW & 0.4 \\
Mean \pm SD & $132.1 \pm 20.2$ & $131.9 \pm 17.2$ & 0.9 & NS \\
\hline Triglyceride (mg/dl): & & & MW & 0.7 \\
Mean \pm SD & $96.2 \pm 23.6$ & $120.0 \pm 29.5$ & 0.4 & NS \\
\hline LDL (mg/dl): & $63.1 \pm 11.4$ & $67.1 \pm 14.6$ & MW & 0.7 \\
Mean \pm SD & & & MW & 0.7 \\
\hline HDL (mg/dl): & $40.7 \pm 9.5$ & $40.7 \pm 9.8$ & 0.4 & NS \\
Mean \pm SD &
\end{tabular}

SD: Standard deviation. $\quad$ MW: Mann Whitney test. $\quad$ NS: Non-significant $(\mathrm{P}>0.05)$

Table (5): Correlation between age and lipid profile in the studied groups

\begin{tabular}{|c|c|c|}
\hline \multirow{2}{*}{ Lipid profile } & \multicolumn{2}{|c|}{ Age } \\
\cline { 2 - 3 } & $\mathbf{r}$ & $\mathbf{P}$ \\
\hline Total cholesterol & -0.31 & $0.2(\mathrm{NS})$ \\
\hline Triglyceride & -0.02 & $0.9(\mathrm{NS})$ \\
\hline LDL & -0.40 & $0.09(\mathrm{NS})$ \\
\hline HDL & -0.07 & $0.8(\mathrm{NS})$ \\
\hline
\end{tabular}

r: Spearman's correlation coefficient. NS: Non-significant $(\mathrm{P}>0.05)$ 
Table (6): Association between sex and lipid profile of the studied groups

\begin{tabular}{||c|c|c|c|c|}
\hline Variables & $\begin{array}{c}\text { Males } \\
(\mathbf{n = 2 2})\end{array}$ & $\begin{array}{c}\text { Females } \\
(\mathbf{n = 2 2})\end{array}$ & $\begin{array}{c}\text { Test of } \\
\text { sig. }\end{array}$ & P \\
\hline Total cholesterol (mg/dl): & & & MW & 0.5 \\
Mean \pm SD & $117.1 \pm 19.6$ & $120.3 \pm 17.2$ & 0.7 & NS \\
\hline Triglyceride (mg/dl): & & & MW & $\mathbf{0 . 0 3}$ \\
Mean \pm SD & $85.2 \pm 20.0$ & $108.7 \pm 25.6$ & 2.1 & S \\
\hline LDL (mg/dl): & $51.0 \pm 11.6$ & $53.5 \pm 11.9$ & MW & 0.3 \\
Mean \pm SD & & & MW & 0.2 \\
\hline HDL (mg/dl): & $49.1 \pm 11.6$ & $45.1 \pm 9.7$ & 1.2 & NS \\
Mean \pm SD &
\end{tabular}

SD: Standard deviation. MW: Mann Whitney test. NS: Non-significant $(\mathrm{P}>0.05)$. S: Statistically significant $(\mathrm{P}<0.05)$.

\section{DISCUSSION}

The clinical manifestation of congenital heart disease differs depending on the type and severity of the defect ${ }^{(7-8)}$. There are several risk factors associated with the development of heart diseases, such as smoking, obesity and dyslipidemia. Dyslipidemia is typically spotted as the most significant factor leading to the development of atherosclerotic diseases, mainly the higher concentrations of low-density lipoproteins (LDL) ${ }^{(9)}$. Few data on the impacts of congenital heart diseases are available with regard to the prevalence of dyslipidemia in children. Our study was done to evaluate the lipid profile in children with congenital heart diseases.

In our study, we found that there was no statistically significant difference between the studied groups regarding demographic characteristics, which is in agreement with the study of Ghaderian et al. ${ }^{(4)}$, who reported that there was no statistically significant difference between the studied groups regarding age and sex. While in Animasahun et al. (10) study, prevalence was more in males and Barbiero et al. ${ }^{(11)}$ study found that most participants were males $(55.7 \%)$, and aged between 6 and 11 years (43.7\%).

Our study showed that the most frequent cardiac defect was ASD (22.7\%) followed by VSD (13.6\%), common A-V canal (9.1\%), mitral regurgitation (9.1\%), pulmonary regurgitation $(9.1 \%)$, and PDA (9.1\%). In contrast to our study, Roy et al. ${ }^{(8)}$ found that the commonest lesion was VSD present in $39.1 \%$ patients followed by PDA in $17.3 \%$, TOF in $15.5 \%$, ASD in $11.8 \%$, A-V canal defect in $0.9 \%$, PS in 1.8 $\%$, $\mathrm{COA}$ in $1.8 \%$, TGA in $1.8 \%$ and single ventricle with single A-V canal defect in $0.9 \%$. While, Ghaderian et al. (4) study showed that VSD, PDA, ASD were the most common heart defects with percentages of $69 \%, 17 \%$ and $10 \%$ of total patient respectively. The differences in this study was due to limited number of cases.

We found that $18.2 \%$ of the studied patients had cyanotic CHD and $81.8 \%$ had non-cyanotic CHD, which is close to the results of Ghaderian et al. ${ }^{(4)}$ who reported that the case group included 22 patients (22\%) with cyanotic CHD and 78 patients (78\%) with acyanotic CHD. In addition, Barbiero et al. ${ }^{(11)}$ found that acyanotic congenital heart disease was presented in $81.1 \%$ of patients while cyanotic congenital heart disease was presented in $18.9 \%$ of patients. While, Singh et al. ${ }^{\left({ }^{(12)}\right)}$ reported that the case group included 4 patients (9.3\%) with cyanotic CHD and 39 (90.7\%) patients with acyanotic CHD. In contrast Animasahun et al. ${ }^{\left({ }^{10)}\right.}$ showed that patients with cyanotic congenital heart disease was presented in $56.1 \%$ of patients.

Our study showed that there was statistically significant differences between the studied groups in lipid profile as case group had higher cholesterol, triglyceride, LDL and lower HDL than control group. Ghaderian et al. ${ }^{(4)}$ study agrees with our results where they reported that serum cholesterol, LDL, and TG concentrations were significantly higher in the patients' group than in the control group ( $\mathrm{p}$ value $<0.05$ ), but disagrees with our study in HDL that was higher in patients' group than in control group. In contrast to our study, Fuenmayor et $\boldsymbol{a l} .{ }^{(13)}$ study showed that dyslipidemia in children with congenital heart diseases revealed rates similar to those found in normal children suggesting that the presence of congenital heart disease does not stand as a risk factor for elevation of LDL.

This study showed that there was no statistically significant difference between cyanotic and noncyanotic CHD in serum lipid profile. This agrees with Ghaderian et al. ${ }^{(4)}$ study, which showed no statistical difference was detected between patients with cyanotic and acyanotic heart defects in correlation to lipid profile. In contrast, researches of Fyfe et al. (14), Perloff et al. ${ }^{(15)}$ and Martínez-Quintana et al. ${ }^{(16)}$ demonstrated that patients with cyanotic heart defects have lower total cholesterol and LDL levels than patients with acyanotic heart defects. It has been explained by that patients with cyanotic CHD have hypoxic erythrocytosis that consequently leads to lower cholesterol levels.

As regards age of children in our study, age was from 2 to 10 years, and there was cross matching in 
choice of age in both groups (patient and control). There was no statistical significance between age and serum lipid profile, but there was a statistically significant association between sex and lipid profile as females had significantly higher serum triglycerides than males. In contrast to our study, Ghaderian et al. ${ }^{(4)}$ found that in patients group, cholesterol, LDL cholesterol, HDL cholesterol, and TG levels were higher in the males than in the females, but the differences between males and females did not reach statistical significance. While Rao and Sastry ${ }^{(17)}$ reported that sex and age are two factors associated with difference in serum lipid profile levels. There is a rising trend begins in early life and continues until the fourth decade then remains unchanged (in healthy individuals). In children between 5 to 10 years old, HDL is higher in boys than in girls. HDL levels increase in girls gradually and decrease in boys after this age through life. Deon $\boldsymbol{e t}$ al. ${ }^{(18)}$ found that there was no significant serum lipid concentration difference was observed between males and females, but mean serum lipid parameters exceeded the 90th percentiles (age and sex related) except for HDL-C, showing normal concentrations, while in study of Animasahun et al. ${ }^{(10)}$ prevalence was more in males.

The differences observed between results of our study and other studies, could be owing to many factors, for example methodology, type of sample (venous/capillary), time interval between last feeding, preparation of feed (dilution) and genetic composition.

\section{CONCLUSION}

We concluded in this study that patients had significantly higher serum lipid levels than age and sex-matched controls. In light of these findings, we recommend screening of lipid profile in children with congenital heart disease to reduce the risk of atherosclerosis. In addition, there was a statistically significant association between sex and lipid profile as females had significantly higher serum triglycerides than males. More studies are needed to determine various affecting factors on lipids in blood and avoid or treat it especially in risky children as who have congenital heart diseases. Moreover, these children must be followed-up.

\section{REFERENCES}

1. Rohit M, Shrivastava S (2018): Acyanotic and Cyanotic Congenital Heart Diseases. Indian J Pediatr., 85 (6): 454-60.

2. Li H, Luo M, Zheng J et al. (2017): An artificial neural network prediction model of congenital heart disease based on risk factors: A hospital-based case-control study. Medicine, 96 (6): 6090-95.

3. Kalra S, Gandhi A, Kalra B (2009): Management of dyslipidemia in children. Diabetol Metab Syndr., 1 (1): $1-5$.

4. Ghaderian M, Emami-Moghadam A, Samir M et al. (2014): Lipid and glucose serum levels in children with congenital heart disease. J Tehran Heart Cent., 9 (1): 20-6.

5. Marelli A, Mackie A, Ionescu-Ittu R et al. (2007): Congenital heart disease in the general population: changing prevalence and age distribution. Circulation, 115 (2): 163-72.

6. Young D (2001): Effects of Disease on Clinical Lab Tests. 4th Edition, AACC, Washington DC. https://www.scirp.org/(S(351jmbntvnsjt1aadkposzje))/ reference/ReferencesPapers.aspx?ReferenceID $=12721$ 86

7. Reda R, Shehab A, Soliman D et al. (2011): Serum visfatin levels in a group of Egyptian obese individuals. Egypt J Immunol., 18 (1): 25-32.

8. Roy K, Shahed M, Roy K et al. (2020): Clinical Presentation and Complications of Different Congenital Heart Disease in Children. Am J Pediatr., 6 (4): 481-7.

9. Nelson R (2013): Hyperlipidemia as a risk factor for cardiovascular disease. Prim Care, 40 (1): 195-211.

10. Animasahun B, Madise-Wobo A, Kusimo O (2017): Cyanotic congenital heart diseases among Nigerian children. Cardiovasc Diagn Ther., 7 (4): 389-96.

11. Barbiero S, D'Azevedo S, Schuh D et al. (2014): Overweight and obesity in children with congenital heart disease: combination of risks for the future? BMC Pediatr., 14: 271-278.

12. Singh $P$, Chaudhuri $P$, Chaudhary A (2017): Incidence of congenital heart disease in children with recurrent respiratory tract infection in tertiary hospital. IOSR JDMS., 16 (9): 42-4.

13. Fuenmayor G, Redondo A, Shirishil K et al. (2013): Prevalence of Dyslipidemia In Children With Congenital Heart Disease. Arq Bras Caridol., 101 (3): 3-276.

14. Fyfe A, Perloff $J$, Niwa $K$ et al. (2005): Cyanotic congenital heart disease and coronary artery atherogenesis. Am J Cardiol., 96: 283-90.

15. Perloff $\mathbf{J}$ (2004): The coronary circulation in cyanotic congenital heart disease. Int J Cardiol., 97: 79-86.

16. Martínez-Quintana E, Rodríguez-González F, Nieto-Lago V et al. (2010): Serum glucose and lipid levels in adult congenital heart disease patients. Metabolism, 59 (11): 1642-8.

17. Rao P, Sastry N (2003): Serum cholesterol levels of males and females in different age groups in South India. Am J Clin Nutr., 33: 181-182.

18. Deon V, Del Bò C, Guaraldi F et al. (2017): Serum lipid profile and fatty acid composition of erythrocyte phospholipids in children and adolescents with primary hyperlipidemia. Int J Food Sci Nutr., 68 (3): 339-48. 